\title{
Female Swimmers' Training Level Estimation on the Basis of Heart Rate Variability Indices Analysis
}

\author{
Bolotin A.E. \\ Peter the Great Saint-Petersburg Polytechnic University \\ Saint Petersburg, Russia \\ a_bolotin@inbox.ru
}

\author{
Ponimasov O.E. \\ A.I. Gertsen Russian State Pedagogical University \\ Saint Petersburg, Russia \\ o-pony@mail.ru
}

\begin{abstract}
The article presents the questions of the training load influence on female athletes, who go in for swimming. We analyzed the training level indices among female athletes in different basic mesocycle phases of autumn-winter training halfcycle. We formed necessary list of heart rate variability indices. They characterize the degree of training load bearing by female athletes. The article presents the order of testing heart rate variability characteristics at rest and during physical load consequences. The results of nervous and hormone regulation of heart rate influence on the training level of female athletes are presented. It is proved that the main index of the training level is the influence of nervous and hormonal components of heart rate regulation synchronization. High degree of synchronization of both heart rate regulation components prove physical load adequacy concerning adaptive reactions of female athletes' organism.
\end{abstract}

Keywords-female athletes; go in for swimming; heart rate regulation indices the training level; physical load.

\section{INTRODUCTION}

Circulatory system of female athletes, who go in for swimming, goes through great functional loads, both during training volumes of the work fulfillment and during the competitions. In this connection systematic control over bearing the training loads by the swimmers is an objective factor of controlling sports training in swimming.

The base of the training process is adaptation to an optimal volume of physical load. It stimulates adaptive reactions of athletes' organism [1, 4].

Adaptive reactivity of athletes' organism is seen in trophic, regulatory and transportation functions of circulatory system improvement [1-5].

When we estimate how swimmers bear training loads it is reasonable to take into account the state of nervous and neurohormonal mechanisms of circulatory system [1,3]. We can see the effectiveness of nervous and neurohormonal regulation synergy of female swimmers according to the results of heart rate fractal analysis on the basis of cardiographic signal variability study. Studying the interaction of nervous and hormonal heart rate regulation among female athletes of different training level, who go in for swimming, can help to solve the problem of physical loads bearing.

The aim of the research is to reveal the differences in the indices dynamics of sympathetic and parasympathetic heart rate regulation among female athletes of different training level, who go in for swimming.

\section{MATERIALS AND METHODS}

Highly-qualified A and B female athletes took part in the research (18 year-old athletes). They trained for the Universiade as a part of the Russia national team in swimming for stayer distances. The research works were held during the basic mesocycle of autumn-winter half cycle after the training at setting and involving mesocycles. The volume of A athlete's fulfilled training load in the introductory part of the mesocycle was $240 \mathrm{~km}$, the volume of B athlete's fulfilled training load was $205 \mathrm{~km}$. During the basic mesocycle overcoming both female athletes fulfilled the same volume and intensity of the training load in water. Cardiogram indices were taken three times a day: two times at rest and once right after the training load. The received results were analyzed by the methods of mathematical statistics.

In order to receive heart rate indices hardware complex "Varicard" was used. With its help studying heart rate variability the authors estimated the parameters of time and frequency range of heart rate intervals. The research results were presented in a form of the detailed information. It reflects the following:

- statistical characteristics of the dynamic range of cardio intervals (heart rate-HR, standard deviation (SD), coefficient of variation (CV));

- cardio intervals distribution as random values (variation pulsogram, MO (mode), AM (amplitude of mode), DMM (Difference between Maximal and Minimal value);

- the activity degree of sympathetic part of vegetative nervous system (rhythmogram of R-R intervals);

- the degree of central control influence on the autonomous level (autocorrelation function);

- the activity of the heart rate control (heart rate spectrum) separate levels. 
Statistical characteristic of the cardio intervals dynamic range was estimated according to difference index of the dynamic range standard deviation duration of different cardio intervals (SDSD) values. SDSD value reflects total effect of the load influence on parasympathetic part of female athletes' vegetative nervous system. SDSD increase proves the increase of autonomous regulation. The decrease shows heart rate sympathetic regulation increase.

Numerical characteristics of vegetative nervous system sympathetic section activity degree were the following: mode (MO), difference between Maximal and Minimal value (DMM) and amplitude of mode (AM).

AM index reflects' centralization increase of heart rate control.

Derived indices of variational heart rate monitor were calculated: tension index of regulatory systems or stress index (SI) and vegetative ratio index (VRI).

Stress-index characterizes activity of sympathetic regulation mechanisms of heart rate and is calculated according to the following formula: $\mathrm{SI}=\mathrm{AM} /(2+\Delta \mathrm{X}+\mathrm{MO})$.

Vegetative ratio index (VRI) determines the ratio of heart rate sympathetic and parasympathetic regulation and is calculated according to the following formula: VRI =АМ/ДХ.

With the help of correlation rithmography method the authors estimated the degree of central (sympathetic) mechanisms influence on the process of heart work selfregulation.

The indices of rhythmogram steepness were studied (IK) (the value of autocorrelation function at the first shift).

In case of high level of interaction between the central and autonomous mechanisms of regulation, steepness (IK) increases.

Spectral analysis of heart rate variability. Spectral analysis use helped to estimate the activity of the separate levels of heart rate control. High frequency components (HF) characterize parasympathetic activity, low frequency (LF) characterize the activity of sympathetic section of vegetative nervous system, very low frequency components (VLF) characterize the processes of dissimilation.

Statistical data handling included arithmetic mean value (x) calculation; standard deviation $(\mathrm{G})$; standard error of the mean value $(\mathrm{m})$; validity of differences according to Student $\mathrm{t}-$ test $(\mathrm{P})$

\section{RESULTS}

Variation pulsometry method helped to compare several indices.

The dynamics of the mode index (AM) amplitude is presented in table I.

AM index characterized the degree of heart rate control centralization among female athletes after the same volume of work fulfillment in water. High value of AM shows B athlete's heart rate sympathetic regulation predominance.
TABLE I. THE DYNAMICS OF FEMALE ATHLETES' CARDIO INTERVALS MODE DISTRIBUTION AMPLITUDE (\%)

\begin{tabular}{|c|c|c|c|c|c|c|}
\hline \multirow{2}{*}{$\begin{array}{c}\text { Female } \\
\text { athletes }\end{array}$} & \multicolumn{6}{|c|}{ Period of testing according to mycrocycles } \\
\cline { 2 - 7 } & \multicolumn{3}{|c|}{1} & \multicolumn{2}{|c|}{2} & \multicolumn{2}{|c|}{3} \\
\cline { 2 - 7 } & At rest & $\begin{array}{c}\text { After } \\
\text { the load }\end{array}$ & At rest & $\begin{array}{c}\text { After } \\
\text { the load }\end{array}$ & At rest & $\begin{array}{c}\text { After } \\
\text { the load }\end{array}$ \\
\hline A & 26,8 & 42,7 & 35,8 & 32,8 & 25,7 & 42,5 \\
\hline B & 40,3 & 30,8 & 25,4 & 34,6 & 23,0 & 25,7 \\
\hline
\end{tabular}

According to the value of cardio intervals standard deviation duration (SDSD) the influence of the load was studied on the functions of the athletes' sympathetic and parasympathetic sections of vegetative nervous system. The dynamics of the athletes some cardio intervals is presented in table II

TABLE II. THE DYNAMICS OF THE FEMALE INDICES SDNN (MS) INDICES

\begin{tabular}{|c|c|c|c|c|c|c|}
\hline \multirow{2}{*}{$\begin{array}{c}\text { Female } \\
\text { athletes }\end{array}$} & \multicolumn{6}{|c|}{ Period of testing according to microcycles } \\
\cline { 2 - 7 } & \multicolumn{3}{|c|}{1} & \multicolumn{2}{|c|}{2} & \multicolumn{2}{|c|}{3} \\
\cline { 2 - 7 } & At rest & $\begin{array}{c}\text { After } \\
\text { the load }\end{array}$ & At rest & $\begin{array}{c}\text { After } \\
\text { the load }\end{array}$ & At rest & $\begin{array}{c}\text { After } \\
\text { the load }\end{array}$ \\
\hline A & 59,8 & 47,7 & 55,7 & 58,3 & 60,7 & 63,4 \\
\hline B & 47,9 & 48,2 & 53,6 & 41,3 & 59,2 & 52,6 \\
\hline
\end{tabular}

B athlete's SDSD index decrease showed that parasympathetic section activity also decreased. It proves the athlete's training level decrease.

Age-related SDSD values showed A athlete's autonomous heart rate rhythm regulation increase.

Tension of regulatory systems index (SI) study shows sufficient activity of heart rate regulation among both female athletes (table III). However, the range of B athlete's SI index changes was considerable. It proves low adaptation to physical load.

\section{TABLE III. ATHLETES' SI (C.U.) INDICES DYNAMICS}

\begin{tabular}{|c|c|c|c|c|c|c|}
\hline \multirow{3}{*}{$\begin{array}{l}\text { Female } \\
\text { athletes }\end{array}$} & \multicolumn{6}{|c|}{ Period of testing according to microcycles } \\
\hline & \multicolumn{2}{|c|}{1} & \multicolumn{2}{|c|}{2} & \multicolumn{2}{|c|}{3} \\
\hline & At rest & $\begin{array}{l}\text { After } \\
\text { the } \\
\text { load }\end{array}$ & At rest & $\begin{array}{l}\text { After } \\
\text { the } \\
\text { load }\end{array}$ & At rest & $\begin{array}{l}\text { After } \\
\text { the } \\
\text { load }\end{array}$ \\
\hline A & 76,8 & 148,6 & 104,5 & 151,6 & 74,2 & 213,8 \\
\hline B & 108,6 & 93,4 & 68,7 & 132,8 & 49,0 & 66,9 \\
\hline
\end{tabular}

The state of athletes' central outline tension was estimated according to IK index (table IV).

TABLE IV. ATHLETES' IK INDICES DYNAMICS

\begin{tabular}{|c|c|c|c|c|c|c|}
\hline \multirow{2}{*}{$\begin{array}{c}\text { Female } \\
\text { athletes }\end{array}$} & \multicolumn{6}{|c|}{ Period of testing according to microcycles } \\
\cline { 2 - 7 } & \multicolumn{2}{|c|}{$\begin{array}{c}\text { After } \\
\text { At rest }\end{array}$} & $\begin{array}{c}\text { At rest } \\
\text { the } \\
\text { load }\end{array}$ & $\begin{array}{c}\text { After } \\
\text { the } \\
\text { load }\end{array}$ & At rest & $\begin{array}{c}\text { After } \\
\text { the } \\
\text { load }\end{array}$ \\
\hline A & 3046,7 & 1978,0 & 2867,4 & 3012,7 & 3176,1 & 2007,4 \\
\hline B & 1387,9 & 1754,8 & 1289,5 & 1154,8 & 1643,9 & 1687,4 \\
\hline
\end{tabular}


- disagreement of nervous and hormonal heart rate regulation provides athletes' adaptive resources decrease.

\section{References}

[1] Bolotin, A.E., Bakayev V.V., Peripheral circulation indices of veteran trail runners. Journal of Physical Therapy Science (JPTS). 2017, vol. 29(2017), no. 6, pp.1092-1094.

[2] Bolotin, A.E., Bakayev V.V., Response of the respiratory system of long and middle distance runners to exercises of different types. Journal of Physical Education and Sport (JPES). 2017, 17(5), Art.231, pp.22142217.

[3] Bunevicius K, Sujeta A, Poderiene K, et al., Cardiovascular reaction to bouts of exercise with blood flow restriction. J. Phys. Ther. Sci. 2016, vol. 12, pp. 3288-3292.

[4] Cooper K., The aerobics program for total well-being. Physical Education and Sport. Moscow. 1989, 224.

[5] Daniel, S., Abnormal blood flow in the sublingual microcirculation at high altitude. Eur. J. Appl. Physiol. 2009, vol. 106, pp. 473-478.

[6] Raspopova E.A., Khorosheva O.A. Health state estimation of swimmersveterans before the important start. The Russian Journal of Physical Education and Sport. 2018, vol. 13(1), pp. 145-148. DOI: 10/14526/01_2018_300
A athlete had VRI index increase after the training. It proves A athlete's sympathetic and parasympathetic heart rate regulation synchronization.

B athlete's VRI index had the tendency to stability or insignificant decrease and it proves inconsistency in heart rate regulation.

As a result A athlete had higher indices of heart rate quick and slow regulation during the whole basic mesocycle, both before and after the training.

A athlete's both regulation components work synchronization and B athlete's disagreement between them show different adaptive reactions of the organism to the load. The first female athlete has higher adaptive ability. The second athlete has lower adaptive ability.

The observed disagreement in the levels of B athlete's neurohormonal regulation is the result of chronic tiredness, caused by long-term influence of excessive physical load. It doesn't correspond with her training level.

\section{CONCLUSION}

It can be stated that the main criterion of the training level is a stable correspondence of heart rate regulation nervous and hormonal components.

Comparative fractal analysis of heart rate variability among highly-qualified female athletes, who go in for swimming, helped to state the following tendencies in heart rate regulation:

- heart rate variability of female athletes depends on coordinated work of nervous and hormonal system of regulation;

- heart rate hormonal regulation indices decrease proves an organism adaptive abilities decrease;

- central regulation of heart activation during stress influence of the load proves imbalance between the processes of energetic assimilation and dissimilation; 